Boise State University

ScholarWorks

Philosophy Faculty Publications and Presentations

Department of Philosophy

$3-1-2016$

From Relative Truth to Finean Non-Factualism

Alexander Jackson

Boise State University 
This is an author-produced, peer-reviewed version of this article. The final, definitive version of this document can be found online at Synthese, published by Springer. Copyright restrictions may apply. doi: 10.1007/s11229-015-0787-0

\title{
From Relative Truth to Finean Non-Factualism
}

\author{
Alexander Jackson \\ Boise State University
}

\begin{abstract}
This paper compares two 'relativist' theories about deliciousness: truth-relativism, and Kit Fine's non-factualism about a subject-matter. Contemporary truth-relativism is presented as a linguistic thesis; its metaphysical underpinning is often neglected. I distinguish three views about the obtaining of worldly states of affairs concerning deliciousness, and argue that none yields a satisfactory version of truth-relativism. Finean non-factualism about deliciousness is not subject to the problems with truth-relativism. I conclude that Finean non- factualism is the better relativist theory. As I explain, non-facualism about deliciousness is happily combined with an invariantist semantics for the word "delicious". On this approach, relativism is a matter for a metaphysical theory, not a linguistic one.
\end{abstract}

\section{Introduction.}

There are several theories in the broadly 'relativist' camp about matters of taste, such as whether the curry I made for dinner is delicious. This paper compares two such theories: truth-relativism, and Kit Fine's (2001) nonfactualism about a subject-matter. I won't address a third kind of relativism, the expressivism of Simon Blackburn (1993) and Allan Gibbard (2003). Contemporary truth-relativism is presented as a linguistic thesis, about how to model the contents of our utterances and judgements. The metaphysical underpinning of the theory is often neglected. ${ }^{1}$ What worldly states of affairs make a judgement true relative to one assessor but false relative to another? I will argue that no satisfactory underpinning can be given. By contrast, Finean non-factualism is in good metaphysical order.

I start in $\$ 2$ by explaining the core motivating thought behind relativism about deliciousness, which I label THE EVENHANDEDNESS MONOLOGUE. While I defend its prima facie plausibility, I do not pretend to prove that some version of relativism about deliciousness is correct; my real question is which version of relativism is best. The paper focuses on relativism about deliciousness. At some points I will assume that the account of deliciousness should plausibly extend to relativism about morality. I will not assume that the account should extend to epistemic modals, for which the linguistic data are more complex. ${ }^{2}$

$\S 3$ introduces the truth-relativist account of THE EVENHANDEDNESS MONOLOGUE, and raises the question of which worldly states of affairs make it the case that a judgement is true relative to a given assessor. $\S \S 4$ and 5 distinguish two such views, arguing they are unsatisfactory. $\S 6$ describes the remaining option for the truth-relativist, and introduces Finean non-factualism about deliciousness. $\S 7$ compares the two views described in $\S 6$, arguing that Finean non-factualism is the more perspicuous and economical theory. Arguably, truth-relativists are motivated by the thought that relativism must be built into the semantics for the relevant parts of natural language. $\S 8$ undermines this motivation. I argue that non-factualism is compatible with an invariantist semantics for "delicious". That semantic theory can take any form that linguists see fit; I'll focus on the direct reference and model-theoretic approaches to semantics. In my view, it is not the job of linguistic theory to say whether relativism is true of deliciousness; it is a job for metaphysics. Finally, $\S 9$ elucidates Finean non-factualism by showing it casts light on some issues in metaphysics that are not directly related to relativism.

\footnotetext{
${ }^{1}$ Exceptions include Boghossian (2010), Einheuser (2008), and Schafer (2014).

${ }^{2}$ As will emerge in $\S 8$, I think there is no distinctive linguistic data in the case of deliciousness and morality. Suppose there is distinctive linguistic data in the case of epistemic modals. Then plausibly the puzzling behaviour of epistemic modals should be treated by a linguistic theory, and relativism about deliciousness and morality by a non-linguistic theory (a metaphysical one). At the very least, we can't assume that deliciousness and epistemic modals should receive a unified treatment. Recent work on epistemic modals includes the essays in Egan \& Weatherson (2011), and MacFarlane (2014 chapter 10).
} 
This is an author-produced, peer-reviewed version of this article. The final, definitive version of this document can be found online at Synthese, published by Springer. Copyright restrictions may apply. doi: 10.1007/s11229-015-0787-0

\section{The Core Relativist Thought.}

Suppose my Dad and I share a curry for dinner. I enjoy the curry, and my Dad doesn't (he doesn't like spicy food). I exclaim, "This curry is delicious!" and my Dad replies, "No it isn't." The central aim of 'relativist' theories about deliciousness is to legitimize my making THE EVENHANDEDNESS MONOLOGUE.

(THE EVENHANDEDNESS MONOLOGUE) The curry is delicious. My Dad's judgement to the contrary is false, and in that sense wrong. But in a deeper, metaphysically serious sense, that's merely what it is 'correct' for me to judge, because the curry tastes good to me. In the metaphysically serious sense it is 'correct' for my Dad to judge that the curry is not delicious, because the curry does not taste good to him. Neither of our judgements is metaphysically privileged.

Plausibly, THE EVENHANDEDNESS MONOLOGUE glosses the motivation of contemporary truth-relativists, including: John MacFarlane (2014) ${ }^{3,4}$ Max Kölbel (2008 p. 250); Karl Schafer (2014 esp. §4) ; Peter Lasersohn (2005 esp. pp. 649, 662); and Tamina Stephenson (2007 pp. 492-3). Setting aside the exegetical question, it is worth investigating whether truth-relativism legitimizes THE EVENHANDEDNESS MONOLOGUE. If it doesn't, truthrelativism turns out to be a half-hearted kind of relativism. ${ }^{6}$ (In his 2003, Kölbel put the relativist thought by saying that my Dad and I are in a 'faultless disagreement'. I don't think it is enough to say my Dad is 'not at fault'. That falls short of the idea that he judges 'correctly'. Indeed, it is hard to hear the claim that my Dad is 'not at fault' without hearing an implication that though blameless, he is incorrect. That thought is compatible with taking there to be objective facts about what's delicious, and so is not characteristic of relativism.)

THE EVENHANDEDNESS MONOLOGUE assumes that my Dad and I disagree about whether the curry is delicious: we take opposing views on that single content. ${ }^{7}$ The assumption is attractive enough to be worth exploring. (Dissenters include Stojanovic 2007, Cappelen \& Hawthorne 2009, ${ }^{8}$ and Sundell 2011.) Whereas truth-relativists typically infer the presence of disagreement from the felicity of certain dialogues, I present it as an intuitively correct psychological description. (Sophisticated arguments in linguistics might affect the ultimate attractiveness of holding my Dad and I disagree about a single content. ${ }^{9}$ ) Another motivation for exploring the hypothesis that my Dad and I disagree is that it would be nice to develop a view that can be extended to the case of morality (that's the endgame here, right?). It is compelling that people disagree about the truth of certain moral claims.

\footnotetext{
${ }^{3}$ MacFarlane (2014) initially presents the idea as the imperative to call something delicious if it is pleasing to you, and call it not delicious if it is not pleasing to you (p. 4; cf. pp. 21-2). He calls an assertion in line with that imperative 'permitted' (pp. 103-111), 'correct' (pp. 73, 200, 306), and 'right' (p. 195). (For reasons I won't go into, MacFarlane (2014 pp. 103-111) says the relativist also gives a distinctive account of when an assertion must be retracted.)

${ }^{4}$ MacFarlane might have endorsed something like THE EVENHANDEDNESS MONOLOGUE earlier work (2007 pp. 28-9). Whether or not MacFarlane (2007 pp. 22-5) had it in mind, consider the alternative view that correctness (in the deep sense) is relative to an assessor. This approach says that relative to me, I'm correct and my Dad's incorrect; relative to my Dad, I'm incorrect and he's correct. On this approach, there is no perspective relative to which both judgements are correct. But that's just not what we want to say. Consider an alternate case in which someone replaces our food with a very bland curry without my Dad or I yet noticing. In the original case, our judgements of deliciousness reflect our own tastes; in this alternate case, our judgements about whether the curry will be delicious are contrary to our own tastes. If correctness is relative to an assessor, then both the original and alternate cases are ones in which my Dad's judgement is correct relative to one of us and incorrect relative to the other. But surely our judgements are worse off in the alternate case than in the original case. Surely the original case is one in which we both judge correctly in the metaphysically serious sense, and the alternate case is one in which we both judge incorrectly.

${ }^{5}$ Schafer says that in the crucial sense, what it is 'permissible' to judge is determined by the judge's tastes (2014 p. 19). He refuses to call permissible judgements 'correct', but I don't think anything deep rests on the point.

${ }^{6}$ I criticize a less demanding desideratum for relativism at the end of $\$ 5$.

${ }^{7}$ MacFarlane (2014 chapter 6) claims that there isn't a single intuitive notion of disagreement about a content. I disagree.

${ }^{8}$ The intuition that we disagree remains strong when we follow Cappelen \& Hawthorne's recommendation not to rely on intuitions about generics, such as whether curry is delicious (not just this one) (2009 pp. 107-9, 111-4). They claim that when I consider that there is a deep sense in which my Dad judges 'correctly', my intuition that we disagree goes away (2009 pp. 119-20). But suppose I am pondering the deeper sense in which my Dad judges 'correctly'. Still, if asked whether I disagree with my Dad about whether the curry is delicious, it seems that I do. I may then say that our disagreement isn't a 'deep' one, as the matter is 'subjective' or 'relative', in a sense that needs explaining, as this paper attempts to do. Cappelen $\&$ Hawthorne also point out that judges realize they shouldn't disagree about whether Ovaltine is delicious, if their pleasure at drinking Ovaltine differs only because one of them always eats dates beforehand, and the other eats chickpeas first (p. 118). The observation is compatible with motivating relativism: those judges should agree that Ovaltine is delicious when drunk after eating dates, and disgusting when drunk after eating chickpeas; no such agreement between my Dad and I suggests itself.

${ }^{9}$ Lasersohn (2009) and Kölbel (2009) give linguistic arguments for an approach on which my Dad and I disagree, and Schaffer (2011 §2) gives linguistic arguments to the contrary.
} 
This is an author-produced, peer-reviewed version of this article. The final, definitive version of this document can be found online at Synthese, published by Springer. Copyright restrictions may apply. doi: 10.1007/s11229-015-0787-0

THE EVENHANDEDNESS MONOLOGUE uses two notions of 'correct' judgement. In the first sense that appears, a judgement is 'correct' if it is true and 'incorrect' if false. Truth and falsity, in this ordinary sense, are 'minimal': <it is true that $\mathrm{p}>$ is equivalent to $\langle\mathrm{p}>$, and $<$ it is false that $\mathrm{p}>$ is equivalent to $<$ not-p $>$. The metaphysical action lies in the second notion of correctness, according to which my Dad makes the 'correct' judgement for him to make, and I make the 'correct' judgement for me to make, though we thereby disagree. It is these claims, involving the second notion of correctness, that are meant to distinguish relativism from objectivism about deliciousness. I will label the relevant notion, which is involved in getting a metaphysical understanding of how our judgements engage with reality, 'metaphysical correctness'. All relativists must deny CORRESPONDENCE:

(CORRESPONDENCE) It is metaphysically correct for a person $\mathrm{J}$ to judge that $\mathrm{p}$ iff: $\mathrm{p}$.

For according to THE EVENHANDEDNESS MONOLOGUE, our judgements are both 'correct', but they are not both true. Objections to relativism that unreflectively assume CORRESPONDENCE fail to consider the view seriously. ${ }^{10}$ On the other hand, more needs to be said to give us a handle on metaphysically correctness, given that it is distinct from truth.

Note that the attraction to saying that my Dad judges 'correctly' may derive from an argument, rather than a raw intuition. MacFarlane (2014 pp. 2-7) gives one such argument; the following footnote gives another. ${ }^{11}$ It becomes important that relativism need not be immediately intuitive when we consider extending it to other domains, such as knowledge (MacFarlane 2014 chapter 8) and morality.

My aim is not to show that THE EVENHANDEDNESS MONOLOGUE must be respected, but to compare the truthrelativist and Finean non-factualist attempts to do so. Nevertheless, let me rebut a simple argument that THE EVENHANDEDNESS MONOLOGUE is incoherent. Paul Boghossian complains that it is "simply obvious" that if my Dad and I both "count as having spoken correctly," then we do not disagree (2010 p. 66). To press the thought: if we can both recognize that the other speaks correctly too, what disagreement is left? I think this objection rests on equivocating between the two notions of correctness in play. Given that I judge that the curry is delicious and my Dad judges it isn't, our differing tastes also make it metaphysically correct for each of us to affirm that the other judges falsely, and is in that sense wrong. Plausibly, that's all it is for us to legitimately disagree about whether the curry is delicious. Our agreement about a different matter (namely which judgements are metaphysically correct) does not remove our disagreement about the matter of taste. It seems relativism can make sense of our disagreeing. However, I will argue that some versions of truth-relativism are deeply in tension with the existence of such disagreement.

\section{Introducing Truth-Relativism.}

Truth-relativists claim that propositions and judgements are true relative to a parameter, such as an assessor or a gustatory standard. In order to ground THE EVENHANDEDNESS MONOLOGUE, they replace CORRESPONDENCE with the following principle.

(TRUTH-RELATIVE CORRESPONDENCE) It is metaphysically correct for a person $\mathrm{J}$ to judge that $\mathrm{p}$ iff: $\mathrm{p}$ is true relative to $\mathrm{J}$.

\footnotetext{
${ }^{10}$ Crispin Wright says that being on one side of a disagreement makes impossible "the kind of even-handed assessment of [the] disagreement that relativism ought intuitively to make possible" (2008 p. 183). He claims that there is no way to have "the appropriate kind of equality of respect for contrasting opinions," as one is "stuck with an opinion of [one's] own on the matter in question" (p. 181). This assumes CORRESPONDENCE. Mark Richard thinks it refutes relativism to observe that I am committed to thinking that my Dad is "mistaken", because "if you have a false belief, you are mistaken" (2008 p. 132). This objection assimilates the relativist's two notions of correctness, i.e. assumes CORRESPONDENCE. Carol Rovane also assimilates the two notions of correctness, charging that THE EVENHANDEDNESS MONOLOGUE incoherently claims that my Dad is and is not wrong (Rovane 2010 p. 48).

${ }^{11}$ There is a raw intuition that my Dad and I disagree about whether the curry is delicious (possibly supported by linguistic arguments). We may then argue that my Dad judges 'correctly' by rejecting non-reductive and reductive realism about deliciousness, and the error theory. Maybe we reject non-reductive realism on the grounds that irreducible facts about what's delicious are not naturalistically respectable. Then we reject reductive realism about deliciousness, according to which what's delicious is determined by what the majority of people find delicious (or: what chemical property "delicious" refers to is determined by what the majority find delicious). For if reductive realism were true, then finding out that the majority of people disagree with you about whether American 'domestic' beer is delicious would force you to change your mind on the matter; but one is not forced by metaphysical considerations to adopt the majority view on such matters. One can dismiss the majority as plebians (cf. Lasersohn 2005 pp. 651-2). Finally, we take it to be an undeniable piece of common-sense that the curry is delicious (or whatever dish or beverage you enjoy), so we reject the error theory. We conclude that judgements of deliciousness do not "aim to correspond to some objective fact of the matter"; rather they "aim to reflect the tastes of the judge". So in the deep sense, my Dad is 'correct' to judge that the curry is not delicious.
} 
This is an author-produced, peer-reviewed version of this article. The final, definitive version of this document can be found online at Synthese, published by Springer. Copyright restrictions may apply. doi: 10.1007/s11229-015-0787-0

For example, the truth relativist says that the proposition that $<$ the curry is delicious $>$ is true relative to me, but its negation is true relative to my Dad. Invoking TRUTH- RELATIVE CORRESPONDENCE, the truth-relativist claims to have thus explained why our conflicting judgements are both 'correct' in the metaphysically serious sense. (See the citations given in $\S 2$.)

I will argue against the truth-relativist account of THE EVENHANDEDNESS MONOLOGUE. Truth-relativism is a view about propositional contents and judgements; it assigns a certain status to representational entities of those kinds. It is natural to wonder how the relative truth of representational entities relates to what reality itself is like. Which worldly states of affairs make a judgement true relative to one assessor but false relative to another? I distinguish three possible answers to this question. Two answers appeal to facts about what's delicious, relativized in distinct ways; I call these views relationalism and holding-relativism. The third answer does not appeal to relativized facts about what's delicious, but rather uses the psychological facts about what people enjoy eating to explain the relative truth of a content or judgement. I call this third view unworldly truth-relativism about deliciousness. ${ }^{12} \S \S 4-7$ argue against each of those approaches. (There is a standard argument in the literature that truth-relativism does not secure disagreement between my Dad and I. I explain why it is not convincing in $\S 6$.)

\section{Truth-Relativism Grounded in Relationalism.}

Relationalism about deliciousness is the most obvious way to relativize the facts about what's delicious. It says that deliciousness is a two-placed relation, which holds between a dish and a person, rather than a property as one naively thinks it to be. (One might think that such a relation is just the psychological relation of a person's enjoying a particular dish. If so, relationalist truth-relativism collapses into unworldly truth-relativism. I won't help myself to this short-cut in arguing against all versions of truth-relativism.)

The relationalist truth-relativist about deliciousness cannot endorse THE EVENHANDEDNESS MONOLOGUE. The truth-relativist component of the view assumes that our ordinary judgements attribute a 1-placed property of deliciousness. For example, I judge that the curry is delicious simpliciter, and my Dad disagrees. ${ }^{13}$ But relationalism says deliciousness is 2-placed, not 1-placed. The view says it is not the case that anything is delicious simpliciter, contrary to my ordinary judgement. Relationalist truth-relativism implies that my ordinary attribution of deliciousness is defective, not correct in the metaphysically deep sense. So the view rejects THE EVENHANDEDNESS MONOLOGUE. The problem is that relationalism is a view about what's delicious, and so can — and does - conflict with our ordinary judgements.

Relationalist truth-relativism about deliciousness is a coherent view-just not one that legitimizes THE EVENHANDEDNESS MONOLOGUE. The view implies that ordinary attributions of 1-placed deliciousness are simply wrong. The claim that ordinary judgements are true relative to their respective judges merely takes some of the sting out of that negative evaluation, showing how the attributions of deliciousness are at least in the ballpark of some fact. This view has some plausibility. (So does the analogous version of Angel Pinillos' 2011 truth-relativism about judgements of duration made by people ignorant of modern physics. ${ }^{14}$ ) However, the project of this paper is to see if there's a version of relativism that doesn't require us to reject the relevant judgements as metaphysically defective. That's partly because I am interested in finding a version of relativism that can also be applied to morality. So I set relationalist truth-relativism aside.

\footnotetext{
12 The view is 'unworldly' in that it does not appeal to worldly facts about what's delicious.

${ }^{13}$ One might think that Stephenson (2007) is a relationalist truth-relativist who denies that our ordinary judgements attribute a 1-placed property of deliciousness. I don't understand the view thus attributed to Stephenson. She thinks many attributions of deliciousness have the content that $X$ is delicious $P R O_{J}$, where $\mathrm{PRO}_{J}$ is a "silent nominal item... that refers to the judge [i.e. the assessor]" (p. 500). Suppose those attributions take deliciousness to be a relation (not a 1-placed property). They relate a dish and...what? Neither a specific judge, nor a function from judges to themselves, are acceptable answers to that question. Maybe Stephenson is best interpreted as taking ordinary attributions of deliciousness to embed a metaphysical mistake (a view I explain in the following paragraph).

${ }^{14} \mathrm{~A}$ fast train makes a circular journey. According to modern physics, the duration of the journey is (in some sense) relative to a frame of reference: a clock on the train should record a shorter time than one on the platform. Pinillos (2011) argues that judges ignorant of the physics attribute unrelativized duration to the journey. He claims it is objectionably uncharitable to (merely) say such judgements are false (p. 66). Rather, such judgements are true relative to some frames of reference. The relationalist truth-relativist says it is not the case that a 2-placed duration relation holds between the journey and some length of time, contrary to our ordinary judgements of duration. Contra Pinillos, this suggests ordinary judgements of duration are defective attempts to get at facts of the form: the journey, $\mathrm{t}$ seconds, and frame $\mathrm{F}$ bear a 3-placed duration relation. Yet the ordinary judgements are in the ballpark of a truth, unlike judgements that someone is a witch. The relationalist attributes relative truth to unqualified attributions of duration to soften the blow of finding them all incorrect.
} 
This is an author-produced, peer-reviewed version of this article. The final, definitive version of this document can be found online at Synthese, published by Springer. Copyright restrictions may apply. doi: 10.1007/s11229-015-0787-0

\section{Truth-Relativism Grounded in Holding-Relativism.}

I think there is another way to relativize facts about what's delicious, which I call 'holding relativism'. Consider first the idea that the way things are is relative to a time. There are two ways to understand the fact that Ella was sat at $10 \mathrm{am}$. The relationalist about time says that the fact concerns the absolute holding of the sitting-at relation between Ella and the time 10am. The holding-relativist says that the state of affairs of [Ella's being sat] holds relative to 10am. (As far as I can see, that's the same as saying that the property of sitting was had-relative-to-10am by Ella.) The two views are different: only the relationalist holds the counter-intuitive view that there are no temporarily had properties, such as being sat. (Fine 2005 pp. 279-80 explores holding-relativism about time.)

Let's use ' $<\mathrm{p}>$ ' to specify propositions, and '[p]' to specify states of affairs. Relationalism about deliciousness says that there are no states of affairs like [the curry is delicious]; but there are states of affairs of the form [the curry is delicious to my Dad], which hold absolutely. Holding-relativism about deliciousness says that states of affairs like [the curry is delicious] hold relative to a person. Let us reserve the term 'state of affairs' for that which holds, either absolutely or relatively, such as n objects bearing an n- ary relation. Let us reserve the term 'fact' for the (relative or absolute) holding of a state of affairs. For example, the holding-relativist says that it is a fact that: [the curry is delicious] holds relative to me, and does not hold relative to my Dad. (If you think holding- relativism is incoherent, that just makes it easier to argue it can't ground a satisfactory truth-relativism. I won't help myself to this shortcut.)

It is useful to think of holding-relativism as an unorthodox version of realism. 'Crude realism' takes it to hold absolutely that [the curry is delicious]. The crude realist about deliciousness posits one realm of fact concerning what's delicious. The holding- relativist posits multiple realms of fact concerning what's delicious, namely what's delicious relative to me, relative to my Dad, and so on.

To get the result that my Dad and I both judge 'correctly', the holding-relativist must say that it is only metaphysically serious to assess my Dad's judgement against one of those realms of fact, namely the states of affairs that hold relative to him. But then it is hard to escape the thought that my Dad and I do not disagree. It is compelling that on this picture, our judgements concern ${ }^{15}$ different aspects of reality. My judgement concerns what's delicious relative to me, and my Dad's judgement concerns what's delicious relative to him. So holding-relativism is deeply in tension with THE EVENHANDEDNESS MONOLOGUE's assumption that my Dad and I disagree. The problem is that holding relativism is too close in subject-matter to the question of what's delicious, and so can - and does - conflict with the ordinary way of assessing other people's judgements. (It would be mistaken to reply that truth-relativists can give an account of disagreement according to which my Dad and I disagree: my point is that such an account seems incompatible with holding relativism.)

The above line of thought is compelling in the most plausible case of holding- relativism, namely the relativity of the way things are to a time. Suppose that at 10am I judge that Ella is sitting, and at 11am my Dad judges that Ella is not sitting. Our judgements are to be assessed with respect to the states of affairs holding at different times (10am and 11 am respectively). My Dad and I clearly do not disagree. ${ }^{16}$ Further, it is plausible that we do not disagree because at $10 \mathrm{am}, \mathrm{I}$ judged that Ella was sitting then. That is, the time the judgement targets is built into the proposition assented to. It seems the holding-relativist should reject the 'temporalist' view that the propositional content of my judgement is just: $<$ Ella is sitting $>$. The metaphysical question as to whether holding- relativism is true should not be confused with the question of what content to attribute to people's mental states. Analogously, it is plausible that holdingrelativism about deliciousness implies the content of my Dad's judgement is that $<$ the curry is delicious relative to $\operatorname{him}>.{ }^{17}$

\footnotetext{
${ }^{15}$ I say our judgements 'concern' different aspects of reality, rather than that they are 'about' them, to allow for the 'temporalist' view of contents described (and rejected) in the next paragraph.

${ }^{16}$ Einheuser (2008) formulates a view like holding-relativism about deliciousness, calling it 'factual relativism'. She admits that on such a view, my Dad and I are judging "about" different aspects of reality (p. 196). She says this is a lesser kind of disagreement than one over a single realm of fact, but is a kind of disagreement nevertheless (p. 193). I think the case of holding-relativism about time shows it is no kind of disagreement at all.

17 I'm rejecting 'non-indexical contextualism' about deliciousness here (MacFarlane $2014 \mathrm{chs} 4-5$ ). According to that view, the propositional content of my judgement is just that the curry is delicious, but my tastes nevertheless determine the truth or falsity of my judgement. On this view, I should think that my Dad's judgement is true, though what he judges is false. I find that an unattractive combination.
} 
This is an author-produced, peer-reviewed version of this article. The final, definitive version of this document can be found online at Synthese, published by Springer. Copyright restrictions may apply. doi: 10.1007/s11229-015-0787-0

Maybe the point should be put more subtly. I suggested at the end of $\S 2$ that legitimate disagreement is a matter of its being metaphysically correct for my Dad to think "No it isn't - you're wrong" when I say that the curry is delicious (and for me to respond similarly to him). Suppose my Dad and I agree that holding-relativism about deliciousness is true. We agree that [the curry is delicious] holds relative to me, and does not hold relative to him, and thus we both judge metaphysically correctly. Then it seems mistaken for each of us to judge that the other judges falsely-it is metaphysically incorrect for us to do so. Even if holding relativism allows that some judges do disagree about what's delicious, it implies they shouldn't. But endorsing the EVENHANDEDNESS MONOLOGUE requires endorsing the practice of disagreeing about what's delicious: it should be metaphysically correct for me to judge that my Dad judges falsely.

As an anonymous reviewer points out, truth-relativists might have a thinner conception of the kind of correctness TRUTH-RELATIVE CORRESPONDENCE concerns. They might distinguish linguistic norms governing how the practice is actually conducted, from an evaluation of whether such a practice is sensible. So it would be 'linguistically correct' for my Dad to say that I judge falsely, even if holding relativism is true and such a linguistic practice is not sensible. ${ }^{18}$ Even if we can distinguish those two kinds of assessment, I think we should take THE EVENHANDEDNESS MONOLOGUE to concern metaphysical correctness, not a thinner kind of 'linguistic' correctness. This paper seeks a version of relativism that legitimizes the ways we think and talk about what's delicious. It's not enough to say that my Dad and I disagree, though only because we are ignorant of the true metaphysics of deliciousness.

\section{Introducing Unworldly Truth-Relativism and Finean Non-Factualism.}

Unworldly truth-relativism says that $<$ the curry is delicious $>$ is true relative to me, but denies that's explained by a corresponding state of affairs concerning deliciousness (relativized in either of the two ways discussed). Rather the proposition that $<$ the curry is delicious $>$ is made true relative to me by psychological facts about what I enjoy eating. ${ }^{19}$ Plausibly, unworldly truth-relativism is what the cited truth-relativists have in mind: they talk about what people enjoy and not about relativized facts about what's delicious. Karl Schafer's 'Metaethical Perspectivalism' is clearly unworldly truth-relativism about morality (2014 p. 80).

I don't think unworldly truth-relativism is refuted by the objection to holding- relativism about deliciousness. Holding relativism is a kind of realism: it explains the metaphysical correctness of our judgements about what's delicious by appeal to facts about what's delicious. That's why it is compelling that our judgements are about those facts, with the consequence that my Dad and I don't disagree. By contrast, unworldly truth-relativism explains the metaphysical correctness of our judgements about what's delicious by appeal to psychological facts about our tastes. One fails to consider the view seriously if one complains that unworldly truth-relativism makes our judgements about our tastes.

The following restatement may help. THE EVENHANDEDNESS MONOLOGUE requires one's metaphysical theory, which should find my Dad's judgement to be 'correct', to be separate from one's 'first-order' gustatory view, which should find my Dad's judgement to be false (say I). Relationalist and holding-relativist truth relativism are unable to maintain the required separation. Relationalism and holding relativism are too close in subject-matter to first-order views, and so conflict with some aspect of our first-order practice. Unworldly truth relativism does not suffer from this defect.

The unworldly truth-relativist can give the following attractive account of disagreement. Suppose that my Dad and I make our respective judgements about the curry, and my tastes make my judgement true relative to me. Then it is also true relative to me that my Dad judges falsely and is in that sense wrong. Similarly, it is true relative to my Dad that I judge falsely and am in that sense wrong. Plausibly, that's all there is to my Dad and I disagreeing about whether the curry is delicious.

\footnotetext{
${ }^{18}$ I am not sure whether the cited truth-relativists have this thin conception of 'correctness'. Schafer says the relevant kind of correctness is that determined by the "fundamental linguistic or conceptual norms" (2014 p. 87). MacFarlane says that it is "constitutive" of assertion and judgement that they are governed by the relevant standard (2014 pp. 101-3).

${ }^{19}$ Unworldly truth-relativism need not deny that states of affairs concerning deliciousness obtain: it can be 'minimalist' about them. That is, the unworldly truth-relativist can say that $<$ [the curry is delicious] holds absolutely $>$ is true relative to me, but false relative to my Dad. The unworldly truth-relativist does not appeal to such states of affairs to explain the relative truth of propositions about what's delicious.
} 
This is an author-produced, peer-reviewed version of this article. The final, definitive version of this document can be found online at Synthese, published by Springer. Copyright restrictions may apply. doi: 10.1007/s11229-015-0787-0

There is a standard complaint in the literature that if TRUTH-RELATIVE CORRESPONDENCE is true, then my Dad and I do not disagree, because our judgements 'concern' our different gustatory standards. ${ }^{20} \mathrm{I}$ have argued that the complaint is a good one against holding-relativism, but fails against unworldly truth-relativism.

(The complaint that TRUTH-RELATIVE CORRESPONDENCE eliminates disagreement is typically pressed as follows (see footnote 21 for citations). Allegedly, the propositional contents of some of our judgements build in neither a possible world nor a time; such contents are only true or false relative to a world and time. But, goes the argument, speakers at different worlds and times do not thereby disagree when one affirms but the other denies such a content. For example, we don't thereby disagree if I believe at 10am that Ella is sitting and you believe at $11 \mathrm{am}$ that she is not sitting. The objector says that given TRUTH-RELATIVE CORRESPONDENCE, deliciousness must be treated analogously, implying my Dad and I do not disagree. MacFarlane (2014 chapters 4-5) now responds by rejecting the supposed analogy between the truth-relativist account of deliciousness and relativity to a world and time. I suggest getting off the boat earlier: truth is not relative to a world or time. Truth-relativists can and should say that times are part of the content of our judgements. Possible worlds usually are not; but contingent contents are not true or false relative to a world. They are absolutely true but could have been absolutely false (or vice versa). So I recommend truth-relativists adopt the position on worlds and times defended by Cappelen \& Hawthorne in a book attacking truthrelativism (2009 pp. 3-4, 94-8). Whether one favours MacFarlane's (2014) response or mine, the objection shows that reflection on worlds and times should in no way 'soften us up' for truth-relativism about deliciousness.)

My objection to unworldly truth-relativism is that it is inferior to Kit Fine's way of formulating 'non-factualism' about a subject-matter (Fine 2001). The Finean idea is to take THE EVENHANDEDNESS MONOLOGUE at face value, theorizing directly in terms of metaphysical correctness. ${ }^{21}$ Finean non-factualism about deliciousness simply says that: the curry tastes good to me, which makes it metaphysically correct for me to judge that it is delicious. The curry tastes bad to my Dad, which makes it metaphysically correct for him to judge that it is not delicious.

Finean non-factualism and unworldly truth-relativism agree that a person's tastes determine whether it is metaphysically correct for them to judge that the curry is delicious. Unworldly truth-relativism explains that claim using relative truth. (There are two ways to do so: either facts about relative truth form an intermediate metaphysical layer between people's tastes and what it is metaphysically correct for them to judge; or else the metaphysical correctness of a judgement just is its truth relative to that judge.) By contrast, Finean non-factualism holds that we should not bring in relative truth to supplement the claims about metaphysical correctness. Rather, metaphysical correctness becomes the central notion used in metaphysical theorizing. (I'll say more about the approach, and explain why it is methodologically sound, in $\S 9$.)

Like the unworldly truth-relativist, the Finean non-factualist has a straightforward account of the disagreement between my Dad and I. Given that we make the relevant judgements, our differing tastes also make it metaphysically correct for each of us to think the other judges falsely and is (in that sense) wrong. On this approach, that's all there is to my Dad and I disagreeing about whether the curry is delicious. Another way to put the point is that Finean nonfactualism has a quasi-realist, 'projectivist' feel, rather than a realist feel. There is nothing problematic about the idea that once one has 'projected' one's tastes, judging things to be delicious or not, one assesses other people's judgements for (minimal) truth and falsity by comparing their judgements to yours. So there is nothing problematic about my Dad and I disagreeing, given Finean non-factualism.

\footnotetext{
${ }^{20}$ The complaint against TRUTH-RELATIVE CORRESPONDENCE is apparently endorsed in earlier work by MacFarlane (2007 pp. $22-5$, cf. footnote 4 above; but not 2014 chapters 4-5), and by Francén (2010 pp. 23-7) and Dreier (2009 pp. 97-100).

${ }^{21}$ Fine describes non-factualism about morality thus:
}

Of course, the obvious standard of correctness [for moral beliefs] will be nonfactual; for the correctness of the judgement that abortion is wrong, say, will simply amount to abortion's being wrong.... But this nonfactual standard of correctness lives in the shadow, as it were, of a factual standard. ... So for the expressivist, for example, the factual standard of correctness for a judgement might be that it faithfully reflects one's (possibly implicit) commitments.... (Fine 2001 p. 23) 
This is an author-produced, peer-reviewed version of this article. The final, definitive version of this document can be found online at Synthese, published by Springer. Copyright restrictions may apply. doi: 10.1007/s11229-015-0787-0

I label a particular view that theorizes in terms of metaphysical correctness 'Finean non-factualism'. Fine himself places some other requirements on a non-factualist account (2001 pp. 21-5). As I explain in the following footnote, I think Fine's extra requirements are mistaken; I will ignore them. ${ }^{22}$ As I explain in $\S 9$, I also disagree with Fine about how best to develop the approach beyond the core stated above. Those matters won't matter for comparing nonfactualism with unworldly truth-relativism.

\section{Comparing Unworldly Truth-Relativism to Finean Non-Factualism.}

I think two types of consideration favour Finean non-factualism over unworldly truth- relativism: Finean nonfactualism is the clearer and more economical theory. The considerations of clarity start with the observation that the truth-relativist must distinguish two notions of truth. The ordinary notion of truth is the 'minimal' one, according to which $<$ it is true that $\mathrm{p}>$ is equivalent to $<\mathrm{p}>$, and $<$ it is false that $\mathrm{p}>$ is equivalent to $<$ not-p $>$. In the ordinary sense, my Dad judges falsely (say I). Truth-relativism must not deny this; so it must be a theory about a different notion of truth, which I label 'truth*'. ('Truth' seems like a fine label for the ordinary notion.) Truth-relativism claims that an attribution of deliciousness is not true* or false* simpliciter, but true* relative to one assessor and false* relative to another. On this approach, the proposition that $<$ it is true that the curry is delicious $>$ is true* relative to me, and false* relative to my Dad. MacFarlane (2014 pp. 37-9, 93-4), Schafer (2014 pp. 76-8), and Kölbel (2008 pp. 250-2) concede the above, granting that truth* is a technical notion.

My first type of reason for preferring Finean non-factualism is that appealing to truth* makes THE EVENHANDEDNESS MONOLOGUE more confusing, not less. This manifests in two ways. Firstly, relativism must distinguish ordinary truth from metaphysical correctness. My Dad's judgement is false (say I), but that's irrelevant to whether it is 'correct' in the sense central to understanding the metaphysics of deliciousness. I think it hinders separating ordinary truth from metaphysical correctness to be told that the latter is a species of truth. (It certainly doesn't help.)

Secondly, it is bewildering hear that truth* is a species of truth, but fundamentally different from ordinary truth. Truth as ordinarily understood is not relative to a judge or anything else. That's why so many philosophers are perplexed to hear that there is a species of truth that is relative to an assessor. It isn't walking like a duck, or quacking like a duck; so it is confounding to be told that it is a kind of duck - just not the ordinary kind. (I don't think the truth of propositions or utterances is relative to a possible world in any interesting sense; rather, what is absolutely true could have been absolutely false. The following footnote rebuts the reply that relative truth* is no more obscure than the notion of truth employed in standard intensional semantics, according to which a sentence-type is true relative to a context of use. ${ }^{23}$ )

I say that appeal to truth*, rather than simply to metaphysical correctness, makes relativism more opaque, not less. The cited truth-relativists are not in a good position to respond to this complaint. They explicate truth* in terms of metaphysical correctness (via TRUTH-RELATIVE CORRESPONDENCE), not vice versa. (MacFarlane 2014 chapter 5; Schafer 2014 §4; Kölbel 2008 p. 250.) They see that the task is to understand how my Dad and I both judge metaphysically correctly (see the citations in $\S 2$ ), and they admit that metaphysical correctness is more easily grasped than relative truth*. So how is it meant to help us understand THE EVENHANDEDNESS MONOLOGUE to bring in relative truth*?

\footnotetext{
22 Fine also requires the non-factualist to say in virtue of what people have beliefs about the subject- matter, without invoking the allegedly nonfactual elements. For example, the moral non- factualist must say in virtue of what people have beliefs about which acts are wrong, without invoking moral wrongness. That strikes me as neither necessary nor sufficient for non-factualism. It is not necessary, because one can think that facts about what people believe are fundamental, and do not hold in virtue of anything else, and yet still be a non-factualist about morality. It is not sufficient, as one can give a functionalist account of what it is to believe something to be good, without mentioning goodness itself, yet be a crude realist about goodness. (Dreier 2004 claims inspiration from Fine 2001, but focuses on what I've argued is the mistaken element in Fine's characterization of non-factualism.)

${ }^{23}$ Intensional semantics employs the notion of a sentence-type being true in a context. This notion (truth3) is not obscure, because it is intimately related to ordinary propositional truth (truth1) and utterance truth (truth2) as follows. Firstly: utterance $u$ is true 2 iff $u$ is an utterance of some sentence-type $s$ such that $s$ is true 3 in the context of utterance of $u$. Secondly: utterance $u$ is true 2 iff $u$ says that $p$ and $p$ is true 1 . Relative truth* cannot be thus domesticated. See Kölbel (2008 §2) for more details. (I am not persuaded by Kölbel's claim (2008 §3) that relative truth* is not obscure because it overlaps with ordinary truth for objective matters.)
} 
This is an author-produced, peer-reviewed version of this article. The final, definitive version of this document can be found online at Synthese, published by Springer. Copyright restrictions may apply. doi: 10.1007/s11229-015-0787-0

Let me add a final variant of the first type of complaint. Given that truth* relative to a judge is not explained by relativized facts about what's delicious, it can only be a kind of assertibility for that judge (it seems to me). That is, truth* relative to a judge is best understood as what it is metaphysically correct for the judge to affirm. But then why call it relative truth* in the first place?

The above complaints are objections to talking about relative truth*. What if the truth-relativist picks a blander label for their central relation? The explanatory structure of the truth-relativist theory is unchanged if we use label ' $\mathrm{T}$ ' for the relation between judges and propositions, instead of 'truth*'. On the view to be considered, my judgement is metaphysically correct because the T relation holds between me and the proposition that $<$ the curry is delicious $>$. Such a theory, which postulates both the $\mathrm{T}$ relation and metaphysical correctness, is less theoretically economical than Finean non-factualism. Finean non-factualism dispenses with the T relation, and claims about it, apparently without cost. Whatever we call it, relative truth* is an unnecessary intermediary between the psychological facts and the metaphysical correctness of judgements. (One could reply that relative truth* is not an intermediary ontologically speaking, because metaphysical correctness just is truth* relative to the judge. This view is particularly vulnerable to the thought that we should just use the terminology of 'metaphysical correctness', which is less confusing than talk of 'relative truth*'. $)^{24}$

I have argued that there is no gain in clarity, nor any explanatory benefit, to using relative truth* to understand THE EVENHANDEDNESS MONOLOGUE. On the contrary, unworldly truth-relativism is more opaque and less explanatorily elegant than Finean non-factualism.

I don't think the cited truth-relativists are motivated to introduce relative truth* by a mistaken assessment of these theoretical virtues. I think they assume that relativism must show up in one's semantic theory. Inspired by Kaplan's framework (1989), they also assume a semantic theory must give some kind of truth-condition to sentences. They conclude that relativism should be formulated as a semantic theory that attributes relative truth*. The next section casts doubt on the assumption that relativism must show up in one's semantic theory. Finean non-factualism about deliciousness is happily combined with a semantics that is silent on metaphysical issues like relativism.

\section{Metaphysics Separated from Linguistics.}

I just suggested that truth-relativism is motivated by the assumption that relativism must take the form of a nonstandard approach to the semantics of natural language. (The expressivism of Blackburn (1993) and Gibbard (2003) also takes a semantic form.) I reject that assumption: Finean non-factualism is a metaphysical theory, and it lets linguists give a semantic theory for a natural language in whatever form they see fit. ${ }^{25}$ To illustrate, I will argue that Finean non-factualism about deliciousness is happily combined with a direct reference or model-theoretic invariantist semantics for the word "delicious". If that's right, the motive for postulating relative truth* is removed.

Finean non-factualism is quasi-realist: it is meant to legitimize our ordinary judgements about the relevant subjectmatter. ${ }^{26}$ The non-factualist holds it is metaphysically correct for me to judge that the curry is delicious. The nonfactualist should also hold it is metaphysically correct for me to judge that the curry has the property of being delicious. The non-factualist should also hold it is metaphysically correct for anyone to judge that: the word "delicious" refers in English to the property of being delicious. So giving a 'direct reference' semantics in that way is compatible with non-factualism about deliciousness.

\footnotetext{
${ }^{24}$ A further point: I think claims about truth* are only used to explain which judgements are metaphysically correct. (Some of those judgements have contents like: $<$ My Dad is wrong $>$, or $<\mathrm{I}$ was wrong $>$.) But the only claims that explain correctness are of the form: $\mathrm{J}_{1}$ 's judgement that $\mathrm{p}$ is true* relative to $J_{1}$. So the truth-relativist theory contains lots of explanatorily idle claims of the form: $J_{1}$ 's judgement that $p$ is true* relative to $J_{2}$, where $\mathrm{J}_{1} \neq \mathrm{J}_{2}$.

${ }^{25}$ A truth-relativist could adopt the approach to semantics I recommend to the Finean non- factualist. That's not the view of the truth-relativists cited, and it would leave truth-relativism unmotivated.

${ }^{26}$ The antifactualist should be a quasi-realist and attribute to the nonfactual all those features that were traditionally thought to belong to the factual ... [Non-factual propositions] will be capable of being true or false, believed or asserted, embedded in larger linguistic contexts, and so on." (Fine 2001 p. 5)
} 
This is an author-produced, peer-reviewed version of this article. The final, definitive version of this document can be found online at Synthese, published by Springer. Copyright restrictions may apply. doi: 10.1007/s11229-015-0787-0

Plausibly, it is also metaphysically correct for anyone to judge that the delicious things form a set. ${ }^{27}$ If so, it is metaphysically correct to judge that the set of delicious things is the extension of the English word "delicious". So giving an extensional model- theoretic semantics is compatible with non-factualism about deliciousness. Of course my Dad and I will disagree about which set is the extension of "delicious"; but that won't impede our collaborative semantic theorizing, any more than does our disagreement about the extension of an objective term like "is over 6 foot tall". We can agree that "delicious" is assigned some set of objects - the delicious ones - and not a semantic value of some other type, and that's enough agreement for the purposes of linguistics.

Nor is there a problem, given non-factualism, with linguists saying that other things could have been delicious, forming a different set than the actually delicious things. For the purpose of capturing content, we can define possible worlds in terms of 'minimal' facts, including whether a particular curry is delicious (Glanzberg 2009 pp. 295-6, 304-5). So it is metaphysically correct for anyone to judge that there is a function that maps pairs, consisting of a possible world and an object, to the True if the object is delicious at that world, and to the False otherwise. We can assign that function as the semantic value of the English word "delicious". So giving an intensional model-theoretic semantics is compatible with non-factualism about deliciousness. Given that we've built facts about what's delicious into our possible worlds, my Dad and I will agree about which function is the semantic value of "delicious", but will disagree about which possible world is actual. Again, this disagreement is irrelevant to our semantic theorizing.

Moving to Kaplan's (1989) framework for understanding indexicality poses no further problem. My Dad and I agree that "delicious" maps every context of use to the same function from worlds and objects to truth-values. That is, we agree that "delicious" gets an invariantist not contextualist semantics (and we agree on exactly what that semantic value is). (Theodore Sider similarly isolates linguistics from metaphysics: 2011 pp. 112-5, 122-4.)

However, I think that the non-factualist must deny that the canvassed approaches to semantics tell us what meanings literally are; rather they give models of meaning that are useful for some explanatory tasks, though not for others. I'll focus on the issue with model-theoretic approaches. The non-factualist takes the content or meaning of "delicious" to be such that the word is metaphysically correctly applied by some judges to some objects, and incorrectly applied on other occasions. But the extension and intension of "delicious" do not determine the conditions for a judge's applying the word metaphysically correctly. So meanings are not literally speaking such sets or functions.

I don't think this is worrying, as long as we can maintain that the relevant sets are useful models of meanings for the purposes of linguistics. They just aren't useful models of meanings for the purposes of metaphysics - specific explanatory purposes warrant specific idealizations. This defence sharply separates the phenomena to be explained by metaphysics from those to be explained by linguistics, of which semantics is a branch. For example, the fact that my $\mathrm{Dad}$ and I can express disagreement about whether the curry is delicious falls under the purview of semantics; but that our judgements are both metaphysically correct falls under the purview of metaphysics. A detailed defence of this separation of subject-matters is beyond the scope of this paper, but let me sketch a line of argument. Semantics should explain how we communicate by exploiting linguistic conventions. I conjecture that there is no difference in kind between how people exploit linguistic conventions to communicate about what's delicious, and about an objective matter such as what's a table. Roughly: people appropriately associate a word with a concept, and take other people to do so too. (Things are more complicated for plenty of other words, including "if" and "most".) If communication works the same way whether the subject-matter is relative or objective, then the relativity of deliciousness should not show up in the model of meaning used by semantics.

I have suggested that a Finean non-factualist can give an invarianist semantics for "delicious" of a familiar kind. Invariantism straightforwardly explains why my Dad and I disagree. Any invariantist view must treat pragmatically certain phenomena some philosophers want to treat semantically. I will briefly consider one example (without pretending to settle it, let alone every case). Stephenson (2007), Cappelen \& Hawthorne (2009 pp. 132-4) and Jonathan Schaffer $(2011$ §2.1) claim that a semantics must explain why "Everyone had a delicious meal" can be used to mean that everyone had a meal that they found delicious, rather than that all the meals were delicious simpliciter. It is independently plausible that this phenomenon is pragmatic (cf. Lasersohn 2005 p. 681, MacFarlane 2014 pp. 155162). Consider the felicity of: "Everyone was given a gold ring that turned out to be brass" (Holton 1997). I don't think the semantic theory should say that "gold" sometimes means gold, and sometimes means taken by some salient person $x$ to be gold. Rather, the latter meaning is sometimes recovered pragmatically as a conversational implicature.

\footnotetext{
${ }^{27}$ I am ignoring certain irrelevant issues, such as the vagueness in how delicious something must be in order to be delicious tout court.
} 
This is an author-produced, peer-reviewed version of this article. The final, definitive version of this document can be found online at Synthese, published by Springer. Copyright restrictions may apply. doi: 10.1007/s11229-015-0787-0

Analogously, the semantics can say that "delicious" means delicious simpliciter, and leave the rest to pragmatics. The analogy is bolstered by the non-literal feel of "Everyone had a delicious meal", supposing the speaker is repulsed by the jellied eels her companions ate and enjoyed.

\section{Developing and Elucidating Finean Non-Factualism.}

How are we to elucidate the notion of metaphysical correctness, and the Finean non- factualist approach? I endorse the methodology articulated by Kit Fine (2001) and Theodore Sider (2011 pp. 8-10). On this approach, metaphysical notions are not to be defined in more familiar terms. Metaphysical notions are clarified by building a theory that links some of them together, and glosses a host of appealing but hazy metaphysical thoughts. It is familiar that some notions are grasped by grasping a theory in which they appear; it is plausible that our grasp of metaphysical notions is tightened in such a manner. Once a metaphysical theory has been presented, we assess whether it sheds light on things. There is no prior question as to whether we understand the notions the theory uses.

The so-called 'problem of creeping minimalism' in meta-ethics (Dreier 2004) illustrates the need for special metaphysical notions. The problem is that expressivism cannot be formulated using familiar ordinary notions, as they apply in the same way to morality as to uncontroversially objective matters. For example, it is an undeniable platitude that there are moral beliefs, which can be true or false. I agree with Fine (2001) that expressivism must therefore be formulated using extra-ordinary, peculiarly metaphysical notions. (I also agree that the relevant notion is that of metaphysically correct judgement: expressivism is best formulated as a particular Finean non-factualist theory about morality. ${ }^{28}$ )

The rest of this section applies the methodology described above. I build a theory about metaphysical correctness, glossing some attractive but hazy metaphysical ideas. In doing so I depart from Fine's views. A clearer metaphysical picture emerges, I hope, thereby improving our grasp on metaphysical correctness.

We can define 'factualism' about a proposition $p$ as the view that what makes a judgement that $p$ metaphysically correct is: that $p$. Non-factualism explains the correctness of a judgement that $p$ in other terms. For example: what makes it metaphysically correct for $\mathrm{J}$ to judge that the curry is delicious is that the curry tastes good to $\mathrm{J}$. We get a nicer package if we are non-factualists about tables, cities, etc., as well as deliciousness. For example: it is the arrangement of particles in a certain region that makes it metaphysically correct for anyone to judge that there's a table there (and metaphysically incorrect for anyone to deny it). This proposal does not collapse the metaphysical difference between deliciousness and tables: unlike judgements about the presence of a table, whether it is correct to attribute deliciousness to a given dish can vary between judges. We can define: 'relativism' is true about a proposition $\mathrm{p}$ iff whether it is metaphysically correct for $\mathrm{J}$ to judge that $\mathrm{p}$ depends on facts about $\mathrm{J}$ (qua judge). So even given nonfactualism about what's delicious and about the presence of tables, only the former subject-matter is relative.

I will describe two advantages to non-factualism about deliciousness, tables, and indeed everything metaphysically non-fundamental. Firstly, it allows us to gloss the hazy metaphysical contrast between something's being a part of reality-as-it-is-in-itself, versus being a human 'projection' onto reality. Let's call the former view 'realism' about a subject-matter. In Fine's (2001) terminology, realism says there are 'facts-in-reality' about the subject-matter. If it is a fact-in-reality that $p$ and one judges that $p$, one thereby 'carves nature at the joints' ${ }^{29}$ Its being a fact-in-reality that $p$ makes it metaphysically correct for anyone to judge that $p$. I accept a converse principle too: if it is not a fact-inreality that $\mathrm{p}$, but it is metaphysically correct for some people to judge that $\mathrm{p}$, then it is something other than $\mathrm{p}$ that makes such judgements correct. For example, it is metaphysically correct for me to judge that the curry is delicious, because I enjoy the curry - not because the curry is delicious. Similarly, it is metaphysically correct for anyone to judge that there is a table here, because of the arrangement of particles in the area-not because there is a table here. These non-factualist accounts gloss the venerable idea that we 'project' deliciousness and tables onto the world. Judgements attributing deliciousness 'project' from our tastes; judgements about tables 'project' from the arrangement of particles. I think this helps make sense of the idea that there are no facts-in-reality about the presence of tables (Fine 2001). ${ }^{30}$

\footnotetext{
${ }^{28}$ As I explain in footnote 22, Dreier (2004) focuses on a mistaken aspect of Fine's account.

29 'Carving nature at the joints' is an expression prominently employed by Sider (2011). I don't mean to endorse his way of precisifying the idea.

${ }^{30}$ Fine (2001) cannot say these nice things because he rejects non-factualism about tables, cities, and the like. He says truths about tables are 'reducible': they are not facts-in-reality, but they are ultimately grounded in facts-in-reality. According to Fine, a reducible truth $\mathrm{p}$ is not a fact-in-
} 
This is an author-produced, peer-reviewed version of this article. The final, definitive version of this document can be found online at Synthese, published by Springer. Copyright restrictions may apply. doi: 10.1007/s11229-015-0787-0

The second advantage of non-factualism about everything other than the facts-in- reality is that, suitably extended, it allows for an attractive treatment of vagueness (spelled out in my MS). The first extension is to assess judgements in a more fine-grained way than simply as being metaphysically correct or incorrect. We assign judgements a degree of goodness, and assess whether they are good enough or 'acceptable'. We also grade the attitude of suspending judgement, and combinations of attitudes. As an example of the latter, it is very bad to: judge that a given shade is red and judge that it is orange. Then we can give non-factualist accounts of vague domains of discourse that say the following three nice things, starting with two conceptions of 'borderline' cases. Firstly, there are some questions for which, for any judge, the underlying facts make either answer metaphysically acceptable. Secondly, there are questions for which suspending judgement is metaphysically acceptable (glossing the intuition that one does not thereby 'miss out on a hidden fact of the matter'). Thirdly, the sorites paradox poses a question to which no response is metaphysically acceptable.

If this account of vagueness is right, then the notions of metaphysically correct or acceptable judgement do a lot of philosophical work. The framework is not justified simply in virtue of its account of deliciousness. In particular, I argue in Jackson (2010) that a similar account of vagueness cannot be given in terms of relative truth. That's an important reason for theorizing in terms of metaphysical acceptability instead.

The following picture might shed light on what we are up to when we talk about metaphysical correctness. Suppose that one thinks that talk about tables, or what's morally wrong, does not carve nature at the joints. We can distinguish two reactions. The 'fundamentalist' temperament is horrified, and concludes that the relevant judgements are illegitimate - in my terms, they are all metaphysically incorrect. That is, the fundamentalist adopts an error theory about the relevant domain of discourse. By contrast, the 'pragmatist' temperament is perfectly relaxed: the relevant judgements are legitimate though they do not carve nature at the joints. The pragmatist owes us an explanation of why such judgements are legitimate, i.e. what makes them metaphysically correct. That is, the pragmatist should give a non-factualist account of the area of discourse. As talk of temperaments and emotional reactions suggests, I am a relativist about metaphysical correctness, as for deliciousness and moral goodness. (More carefully: I am a relativist about the metaphysical correctness of judgements that do not carve nature at the joints. When it is a fact-in-reality that $\mathrm{p}, \mathrm{p}$ makes it correct for anyone to judge that $<$ it is metaphysically correct for anyone to judge that $\mathrm{p}>$.)

This section sketched a theory framed in terms of metaphysically correct or acceptable judgement. If one understands the theory and finds it illuminating, then the same goes for the central notion it employs. There is no other way, I suggest, to clarify metaphysical concepts. Of course a philosopher could insist that she just doesn't get what I've been talking about. But such a philosopher will have no sympathy for the project of making sense of THE EVENHANDEDNESS MONOLOGUE. Those of us who are sympathetic to relativism, and the other metaphysical ideas I've talked about in this section, should keep our nerve and get on with the task of building an attractive metaphysical picture.

\section{Conclusion.}

THE EVENHANDEDNESS MONOLOGUE captures the core relativist thought about deliciousness. I distinguished three ways of relating relative truth to worldly states of affairs. I argued that the relativist should reject all three versions of truth-relativism in favour of theorizing directly in terms of metaphysically correct judgement, in the manner of Kit Fine's non-factualist. While metaphysically bold, the approach is linguistically conservative. ${ }^{31}$

\footnotetext{
reality, but our judgements that $\mathrm{p}$ are still made metaphysically correct or not by whether $\mathrm{p}$. (Reducible truths are still 'factual'.) That is, our judgements are to be understood metaphysically as engaging with p's being the case. We don't 'project' tables onto the world, but neither are they constituents of any facts-in-reality. I find this combination baffling; things are clearer if we reject Fine's category of 'reducible' truths.

${ }^{31}$ I would like to thank the following for helpful comments and conversations: Corine Besson, Andrew Cortens, Stephen Crowley, Kit Fine, John Hawthorne, Brian Kierland, Angel Pinillos, Ted Sider, Ernie Sosa, several anonymous reviewers, and those attending a meeting of the LEM forum at the University of London's Institute of Philosophy.
} 
This is an author-produced, peer-reviewed version of this article. The final, definitive version of this document can be found online at Synthese, published by Springer. Copyright restrictions may apply. doi: 10.1007/s11229-015-0787-0

\section{References}

Blackburn, Simon. 1993. Essays in Quasi-Realism, OUP.

Boghossian, Paul. 2010. “Three Versions of Relativism.” In ed. S. Hales, Blackwell Companion to Relativism, Blackwell.

Cappelen, Herman, \& Hawthorne, John. 2009. Relativism and Monadic Truth, OUP. Dreier, James. 2004. "MetaEthics and the Problem of Creeping Minimalism." Philosophical Perspectives 18, pp. 23-44.

---- 2009. "Relativism (and Expressivism) and the Problem of Disagreement." Philosophical Perspectives 23, pp. 79-110.

Egan, Andy, \& Weatherson, Brian (eds). 2011. Epistemic Modality, OUP.

Einheuser, Iris. 2008. "Three Forms of Truth Relativism.” In eds. Kölbel \& Garcia- Carpintero, Relative Truth, OUP.

Fine, Kit. 2001. "The Question of Realism.” Philosophers’ Imprint 1/1.

--- 2005. "Tense and Reality." Chapter 8 in his Modality and Tense, OUP.

Francén, Ragnar. 2010. "No Deep Disagreement for New Relativists." Philosophical Studies 151, pp. 19-37.

Gibbard, Alan. 2003. Thinking How to Live, Harvard UP.

Glanzberg, Michael. 2009. "Semantics and Truth Relative to a World." Synthese 166, pp. 281-307.

Holton, Richard. 1997. "Some Telling Examples: Reply to Tsohatzidis." Journal of Pragmatics 28, pp. 625-8.

Jackson, Alexander. 2010. "The Inflexibility of Relative Truth.” Proceedings of the Aristotelian Society 110(3), pp. 407-419.

--- $\quad$ MS. "Shall we stop trying to solve the sorites paradox?"

Kaplan, David. 1989. "Demonstratives: An Essay on the Semantics, Logic, Metaphysics, and Epistemology of Demonstratives and Other Indexicals." In eds. Almog, Perry, \& Wettstein, Themes From Kaplan, OUP.

Kölbel, Max. 2003. "Faultless Disagreement." Proceedings of The Aristotelian Society 104:1, pp. 53-73.

--- $\quad$ 2008. "Truth in Semantics." Midwest Studies in Philosophy 32, pp. 242-257.

--- $\quad$ 2009. "The Evidence for Relativism." Synthese 166:2, pp. 375-395.

Lasersohn, Peter. 2005. "Context Dependence, Disagreement, and Predicates of Personal Taste." Linguistics and Philosophy 28:6, pp. 643-686.

--- $\quad$ 2009. "Relative Truth, Speaker Commitment, and Control of Implicit Arguments." Synthese 166:2, pp. $359-374$.

MacFarlane, John. 2007. "Relativism and Disagreement.” Philosophical Studies 132, pp. 17-31.

--- $\quad$ 2014. Assessment Sensitivity: Relative Truth and Its Applications, OUP.

Pinillos, Angel. 2011. "Time Dilation, Context and Relative Truth." Philosophy and Phenomenological Research $82: 1$, pp. 65-92.

Richard, Mark. 2008. When Truth Gives Out, OUP.

Rovane, Carol. 2010. "Relativism Requires Alternatives, Not Disagreement or Relative Truth." In ed. S. Hales, Blackwell Companion to Relativism, Blackwell.

Schafer, Karl. 2014. "Constructivism and Three Forms of Perspective-Dependence." Philosophy and Phenomenological Research 89:1, pp. 68-101.

Schaffer, Jonathan. 2011. "Perspective in Taste Predicates and Epistemic Modals." In eds. Egan \& Weatherson, Epistemic Modality, OUP.

Sider, Theodore. 2011. Writing the Book of the World, OUP.

Stephenson, Tamina. 2007. "Judge Dependence, Epistemic Modals, and Predicates of Personal Taste." Linguistics and Philosophy 30:4, pp. 487-525.

Stojanovic, Isidora. 2007. "Talking About Taste: Disagreement, Implicit Arguments, and Relative Truth.” Linguistics and Philosophy 30:6, pp. 691-706.

Sundell, Timothy. 2011. "Disagreements and Taste." Philosophical Studies 155:2, pp. 267- 288.

Wright, Crispin. 2008. "Haphazard Thoughts About Relativism About Truth Itself." In eds. Kölbel \& GarciaCarpintero, Relative Truth, OUP. 